\title{
Characterization of Ribose-5-Phosphate Isomerase B from Newly Isolated Strain Ochrobactrum sp. CSL1 Producing L-Rhamnulose from L-Rhamnose
}

\author{
Min Shen ${ }^{1 \dagger}$, Xin $\mathrm{Ju}^{1 \dagger}$, Xinqi $\mathrm{Xu}^{2}$, Xuemei $\mathrm{Yao}^{1}$, Liangzhi $\mathrm{Li}^{1 *}$, Jiajia Chen ${ }^{1}$, Cuiying $\mathrm{Hu}^{1}$, Jiaolong $\mathrm{Fu}^{1}$, and \\ Lishi Yan ${ }^{1}$ \\ ${ }^{1}$ School of Chemistry, Biology, and Material Engineering, Suzhou University of Science and Technology, Suzhou 215009, P.R. China \\ ${ }^{2}$ Fujian Key Laboratory of Marine Enzyme Engineering, Fuzhou University, Fujian 350116, P.R. China
}

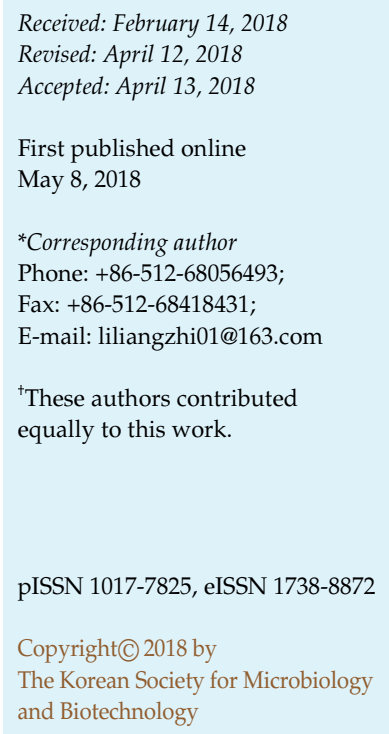

\begin{abstract}
In this study, we attempted to find new and efficient microbial enzymes for producing rare sugars. A ribose-5-phosphate isomerase B (OsRpiB) was cloned, overexpressed, and preliminarily purified successfully from a newly screened Ochrobactrum sp. CSL1, which could catalyze the isomerization reaction of rare sugars. A study of its substrate specificity showed that the cloned isomerase (OsRpiB) could effectively catalyze the conversion of L-rhamnose to L-rhamnulose, which was unconventional for RpiB. The optimal reaction conditions $\left(50^{\circ} \mathrm{C}\right.$, $\mathrm{pH}$ 8.0, and $1 \mathrm{mM} \mathrm{Ca}{ }^{2+}$ ) were obtained to maximize the potential of OsRpiB in preparing L-rhamnulose. The catalytic properties of OsRpiB, including $K_{\mathrm{m}}, k_{\mathrm{cat}}$ and catalytic efficiency $\left(k_{\text {cat }} / K_{\mathrm{m}}\right)$, were determined as $43.47 \mathrm{mM}, 129.4 \mathrm{sec}^{-1}$, and $2.98 \mathrm{mM} / \mathrm{sec}$. The highest conversion rate of L-rhamnose under the optimized conditions by OsRpiB could reach $26 \%$ after $4.5 \mathrm{~h}$. To the best of our knowledge, this is the first successful attempt of the novel biotransformation of L-rhamnose to L-rhamnulose by OsRpiB biocatalysis.
\end{abstract}

Keywords: L-rhamnose, L-rhamnulose, Ochrobactrum sp. CSL1, rare sugar, ribose-5-phosphate isomerase B

\section{Introduction}

Rare sugars, defined by the International Society of Rare Sugar, have drawn increased attention because of their promising beneficial effects [1,2]. A large part of monosaccharides, including all L-hexoses and nine pentoses, are regarded as rare sugars. Besides these, deoxygenated monosaccharides, as a member of rare sugars, are also vital as recognition elements in bioactive molecules [3]. L-Rhamnulose (6-deoxy-L-fructose), as one of the rare deoxy ketoses, is widely used in the food industry. As a starting material for preparing food flavors, it has been used widely because of its caramel-like aroma [4]. Moreover, it can be directly isomerized or epimerized into other rare sugars [5].

Rare sugars can hardly be extracted from natural sources and have to be produced via chemical or biological reactions [3]. As a result, effective processes are needed for producing deoxy ketoses in considerable amounts [5]. Previously, deoxy ketoses were generally synthesized via chemical reactions. However, these reactions had low specificity, resulting in long synthetic routes, and involved the use of hazardous reagents, causing environmental issues. The biotechnological method using enzymatic reactions to produce rare sugars is environment-friendly and hence has gained enormous attention [6]. For example, the biotechnological production of L-rhamnulose could be catalyzed by L-rhamnose isomerase (L-RhI) from Dictyoglomus turgidum [7]. Recently, a new two-step strategy for L-rhamnulose production based on the concept of a "phosphorylation and dephosphorylation" cascade reaction was reported. In this strategy, L-rhamnose was first isomerized to phosphorylated L-rhamnulose by substrate-specific Lrhamnulose kinase in a phosphorylation reaction. Then, the phosphate group was hydrolyzed to produce L-rhamnulose 
with high purity and yield [5].

Ribose-5-phosphate isomerase B (RpiB) has been implicated in the production of rare sugars in recent years. A series of RpiBs from different strains were reported to have a wide substrate spectrum and have been applied in rare sugar production. For example, D-allose could be prepared by RpiB from Thermotoga lettingae TMO, Clostridium thermocellum [8, 9], Clostridium difficile, and T. maritima [10]. Furthermore, L-lyxose and L-tagatose could be prepared by RpiB from Streptococcus pneumoniae [11]. However, the approaches to the production of deoxy rare sugars, such as L-rhamnulose, catalyzed by RpiB have not been reported yet.

In this study, RpiB from a newly isolated bacterium Ochrobactrum sp. CSL1 (OsRpiB) was cloned and overexpressed in Escherichia coli BL21 (DE3). The substrate spectrum of OsRpiB was studied to investigate its catalytic properties, and the unconventional conversion of L-rhamnose into L-rhamnulose was found. Different reaction conditions and kinetic parameters for L-rhamnulose isomerization were evaluated to investigate this unconventional reaction. The efficiency for conversion of L-rhamnose into L-rhamnulose using OsRpiB under optimized conditions was determined.

\section{Materials and Methods}

\section{Materials}

Standard substances such as L-rhamnulose and L-rhamnose were purchased from Sigma-Aldrich (USA). Electrophoresis reagents, the genomic DNA minipreparation kit with a spin column, the polymerase chain reaction (PCR) kit, and isopropyl $\beta$-D-1thiogalactopyranoside (IPTG) were purchased from Beyotime Institute of Biotechnology (China). Restriction enzymes and T4 DNA ligase were purchased from New England Biolabs (USA). A DNA gel extraction kit was purchased from Generay Biotech (China). A universal DNA purification kit was obtained from Tiangen Biotech Co., Ltd. (China). All other reagents (analytical grade) were purchased from Sinopharm Chemical Reagent Co., Ltd. (China).

\section{Bacterial Strains, Plasmid, and Culture Conditions}

The genomic DNA of Ochrobactrum sp. CSL1, Escherichia coli BL21 (DE3) cells, and plasmid vector pET-28a were used as the source of OsRpiB gene, host cells, and expression vector, respectively. Ochrobactrum sp. CSL1, which was used as the DNA manipulation source in this study, was isolated from flowers planted in the Shangfang Mountain National Forest Park (Suzhou, China) using L-ribose as the sole carbon source. The isolation medium for strain selection was composed of $0.26 \%\left(\mathrm{NH}_{4}\right)_{2} \mathrm{SO}_{4}$ $0.24 \% \mathrm{KH}_{2} \mathrm{PO}_{4}, 0.56 \% \mathrm{~K}_{2} \mathrm{HPO}_{4}, 0.01 \% \mathrm{MgSO}_{4} \cdot 7 \mathrm{H}_{2} \mathrm{O}, 0.05 \%$ yeast extract, and $0.5 \%$ L-ribose [12]. The strain was identified using the 16S rDNA method (GenBank ID MG008507.1). The recombinant
E. coli for protein expression was cultivated in a Luria-Bertani (LB) medium with $50 \mu \mathrm{g} / \mathrm{ml}$ kanamycin at $37^{\circ} \mathrm{C}$ with shaking at $200 \mathrm{rpm}$. IPTG was added to the culture medium to a final concentration of $0.4 \mathrm{mM}$ to induce RpiB expression when the $\mathrm{OD}_{600}$ reached $0.6-0.8$. Then, the culture was grown at $16^{\circ} \mathrm{C}$ and $200 \mathrm{rpm}$ for $20 \mathrm{~h}$.

\section{Construction of Recombinant Strain}

Total genomic DNA of Ochrobactrum sp. CSL1 was extracted using the genomic DNA mini preparation kit with a spin column. The gene encoding a putative protein, previously proposed as ribose-5-phosphate isomerase, was amplified by PCR using Ochrobactrum sp. CSL1 genomic DNA as the template. The designed sequence of the oligonucleotide primers used for gene cloning was based on the DNA sequences of ribose-5-phosphate isomerase from Ochrobactrum anthropi ATCC49188 (GenBank ID5379879 and ID5382335). Forward (5'-ATGCGAATTCATGAT GAAAGTAGCAGTAGCAGG-3') and reverse (5'-GCATAAGCT TTCAGCCCTTGTTGTACTTCGC-3') primers were designed to introduce the EcoRI and HindIII restriction sites (underlined), respectively.

The PCR amplification of OsRpiB from Ochrobactrum sp. CSL1 was performed with corresponding primers using BeyoTaq DNA polymerase. The PCR conditions were as follows: initial denaturation $\left(5 \mathrm{~min}\right.$ at $\left.94^{\circ} \mathrm{C}\right), 30$ cycles of denaturation $\left(30 \mathrm{sec}\right.$ at $\left.94^{\circ} \mathrm{C}\right)$, annealing (30 sec at $\left.55^{\circ} \mathrm{C}\right)$, elongation $\left(80 \mathrm{sec}\right.$ at $\left.72^{\circ} \mathrm{C}\right)$, and a final extension step $\left(10 \mathrm{~min}\right.$ at $\left.72^{\circ} \mathrm{C}\right)$. The PCR products were purified using a universal DNA purification kit and sequenced.

The purified PCR products and the plasmid pET-28a were separately cut with the restriction enzymes EcoRI and HindIII at $37^{\circ} \mathrm{C}$. The restriction-digested DNA products were purified using a universal DNA purification kit. The expression plasmid pET-28a digested with the same restriction enzymes was purified using a DNA gel extraction kit. To construct recombinant plasmids, the purified PCR products were ligated to the plasmid pET-28a, which added His-tag sequences on the $N$-terminal of target protein. After ligation, recombinant plasmids were transformed into E. coli BL21(DE3) and cultivated on LB agar plates with $50 \mu \mathrm{g} / \mathrm{ml}$ kanamycin. The transformants were identified by colony PCR identification and sequencing by Sangon Biotech (China).

\section{Purification and Estimation of OsRpiB}

Bacterial cells were harvested from the culture broth by centrifugation $\left(4^{\circ} \mathrm{C}, 4,000 \times g, 10 \mathrm{~min}\right)$ and resuspended in ice-cold lysis buffer $(25 \mathrm{mM}$ Tris- $\mathrm{HCl}$ at $\mathrm{pH} 7.5,500 \mathrm{mM} \mathrm{NaCl}, 10 \%$ glycerol, and $1 \mathrm{mM}$ dithiothreitol). The cell suspensions were homogenized using a cell disruptor (Homogenizers, High-Pressure EmulsiFlex-C3; Avestin, Canada) three times and centrifuged at $40,000 \times g$ for $1 \mathrm{~h}$ at $4^{\circ} \mathrm{C}$. The column purification step was carried out at $4^{\circ} \mathrm{C}$ with a fast protein liquid chromatography system (BioRad, USA). First, proteins were purified through a $5 \mathrm{ml}$ HisTrap FF chromatography column (GE Healthcare, USA) and eluted with $250 \mathrm{mM}$ imidazole in a buffer containing $25 \mathrm{mM}$ Tris- $\mathrm{HCl}$ 
$(\mathrm{pH} 7.5)$ and $250 \mathrm{mM} \mathrm{NaCl}$. Then, the proteins were further purified by a HiLoad Superdex S-75 26/60 column (GE Healthcare, USA) in a buffer containing $25 \mathrm{mM}$ Tris- $\mathrm{HCl}$ (pH 7.5), and $500 \mathrm{mM}$ $\mathrm{NaCl}$. Finally, the active fractions were collected, dialyzed against stabilization buffer $(20 \mathrm{mM}$ Tris- $\mathrm{HCl}$ at $\mathrm{pH} 7.0$ and $50 \mathrm{mM}$ $\mathrm{NaCl}$ ), and concentrated to $10 \mathrm{mg} / \mathrm{ml}$ in a Centriprep-30 tube with an Ultracel-30 membrane (Merck Millipore, Germany). The concentrations of proteins were determined according to the Bradford method with bovine serum albumin as the standard [13]. The purified RpiB was checked by sodium dodecyl sulfatepolyacrylamide gel electrophoresis (SDS-PAGE) to obtain the apparent subunit molecular mass, and standard markers (molecular range $10-180 \mathrm{kDa}$ ) were used to determine the approximate molecular masses. Moreover, the samples were also analyzed by $12 \%$ native-PAGE.

\section{Gel Permeation Chromatography Coupled with Multiangle Laser Light Scattering (GPC-MALLS)}

The active OsRpiB molecular mass was also measured by GPCMALLS. Namely, the absolute molecular mass distribution of OsRpiB was measured by a Waters GPC system using a Shodex OHpak SB-803 HQ chromatography column $(8 \times 300 \mathrm{~mm})$ at the flow rate of $1 \mathrm{ml} / \mathrm{min}$; the column was eluted at $25^{\circ} \mathrm{C}$ with $20 \mathrm{mM}$ PBS ( $\mathrm{pH}$ 8.0) as the eluant. A MALLS photometer (DAWNDSP, Wyatt Technology, USA), and an OptiLab Rex (Wyatt Technology, USA) differential refractive index (RI) detector were used to monitor the elution from the column. The molecular weight of the eluted protein was calculated from the data collected with the RI detector and MALLS photometer using ASTRA software (ver. 6.0.2; Wyatt Technology, USA).

\section{Enzyme Activity}

L-rhamnose was used as the substrate for enzyme activity assay. The OsRpiB activity was assayed by measuring the increase in the product, L-rhamnulose, in the reaction mixture containing $50 \mathrm{mM}$ phosphate buffer $(\mathrm{pH} \mathrm{8.0)}$ and an appropriate amount of the enzyme in a final volume of $1 \mathrm{ml}$ at $50^{\circ} \mathrm{C}$. L-Rhamnulose was detected and determined by both high-performance liquid chromatography (HPLC) and the cysteine-carbazole method [14, 15]. One unit (U) of enzyme activity was defined as the amount of enzyme required to produce $1 \mu \mathrm{mol}$ of L-rhamnulose from L-rhamnose in $1 \mathrm{~min}$.

\section{Determination of Enzymatic Properties}

The activity of OsRpiB was evaluated at $50^{\circ} \mathrm{C}$ in a range of $\mathrm{pH}$ 6.0-9.0 and then in $50 \mathrm{mM}$ phosphate buffer ( $\mathrm{pH}$ 8.0) at temperatures ranging from $30^{\circ} \mathrm{C}$ to $80^{\circ} \mathrm{C}$ to determine the effect of $\mathrm{pH}$ and temperature on the activity. The experiment was performed in the presence of various divalent metal ions $\left(\mathrm{Mg}^{2+}, \mathrm{Mn}^{2+}, \mathrm{Zn}^{2+}, \mathrm{Ca}^{2+}\right.$, $\mathrm{Cu}^{2+}$, and $\left.\mathrm{Ba}^{2+}\right)$ at a final concentration of $1 \mathrm{mM}$ to study the influence of metal cations on the enzymatic activity. Then, $6 \mathrm{mM}$ of each substrate was used to investigate the substrate specificity of the enzyme. The OsRpiB activity was measured in $50 \mathrm{mM}$ phosphate buffer ( $\mathrm{pH}$ 8.0) containing different substrates (D-allose, D-arabinose, D-ribose-5-phosphate, L-ribose, and L-rhamnose). The reaction was performed at $50^{\circ} \mathrm{C}$ for $5 \mathrm{~min}$, and the formation of ketose was determined by the cysteine-carbazole method. Kinetic parameters were also determined in $50 \mathrm{mM}$ phosphate buffer (pH 8.0) using 6-300 mM L-rhamnose and with ketose formation determined by the cysteine-carbazole method. Kinetic parameters, such as $K_{\mathrm{m}}(\mathrm{mM})$ and $v_{\max }(\mu \mathrm{mol} / \mathrm{min} / \mathrm{mg})$ for L-rhamnose were calculated using Lineweaver-Burk plots.

\section{Analytical Methods}

The isomerization products of monosaccharides were detected using HPLC. The reaction was stopped by incubating the mixture in boiling water for $5 \mathrm{~min}$, and then the mixture was centrifuged at $12,000 \times g$ for $5 \mathrm{~min}$ to remove the enzyme. The supernatants were filtered through a $0.22-\mu \mathrm{m}$ membrane and analyzed by HPLC (Agilent 1120; Agilent Technologies Inc., USA) with a refractive index detector using a Sugar-Pak column $\left(6.5 \times 300 \mathrm{~mm}^{2}\right.$; Waters, USA), which was eluted at $80^{\circ} \mathrm{C}$ with ultrapure water at a flow rate of $0.5 \mathrm{ml} / \mathrm{min}$.

\section{Results and Discussion}

\section{Cloning, Expression, and Purification of OsRpiB}

Recombinant OsRpiB was cloned, expressed, and purified as described in the Materials and Methods section. The molecular mass of the enzyme was estimated to be approximately $19 \mathrm{kDa}$ by SDS-PAGE, which was consistent

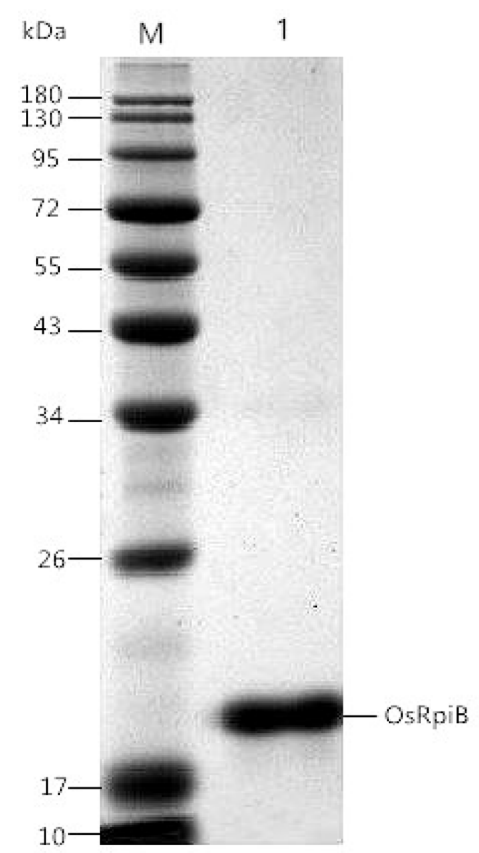

Fig. 1. SDS-PAGE analysis of purified recombinant OsRpiB. Lane M: marker proteins; Lane 1: purified OsRpiB. 
with the calculated value of $19.4 \mathrm{kDa}$ based on the $152-$ amino-acid and 6 histidine sequences (Fig. 1). These results showed that the recombinant Ochrobactrum sp. CSL1 RpiB was successfully overexpressed in E. coli BL 21(DE3).

\section{Sequence Analysis of OsRpiB}

Based on the sequence information analysis, OsRpiB belongs to the LacAB/RpiB superfamily (PFAM PF02502), which contains RpiB, galactose isomerase subunit $A$, and galactose isomerase subunit B [16]. Recently, several conserved amino acids of RpiB from Leishmania donovani were noted in a mutational analysis (i.e., Cys69, His11, His102, His138, Asp45, Tyr46, Pro47, and Glu149) to gain crucial insights into their roles in substrate binding, catalysis, and conformational stability of the enzyme [17]. In this study, the obtained OsRpiB gene contained 459 base pairs encoding a protein of 152 amino acid with a calculated molecular mass of $19.4 \mathrm{kDa}$ (Fig. 2). The molecular mass of E. coli RpiB was determined as 32-34 kDa [18]. Furthermore, the molecular mass of purified OsRpiB was determined by gel permeation chromatography. As the results in Fig. 3A show, the purified OsRpiB had a peak at $14.30 \mathrm{~min}$. The absolute molecular mass of OsRpiB under active protein was around $72 \mathrm{kDa}$. Obviously, these results clearly suggest that the purified OsRpiB is a homotetramer. In addition, the purified OsRpiB was also analyzed by native-PAGE (Fig. 3B). It also showed a molecular mass of around $72 \mathrm{kDa}$, which was in good agreement with the calculated molecular mass by gel permeation chromatography.

The amino acid sequence of OsRpiB has 41\%, 41\%, 37\%, $31 \%$, and $38 \%$ identity with RpiBs from C. acetobutylicum, C. thermocellum, T. maritima, Mycobacterium tuberculosis, and Pseudothermotoga lettingae, respectively. The amino acid sequence alignment of OsRpiB and other RpiBs was performed using ClustalX 2.1 software and generated using BOXSHADE (https://embnet.vital-it.ch/software/ BOX_form.html). The results of sequence analysis indicated that different RpiBs had low homology (less than 50\%
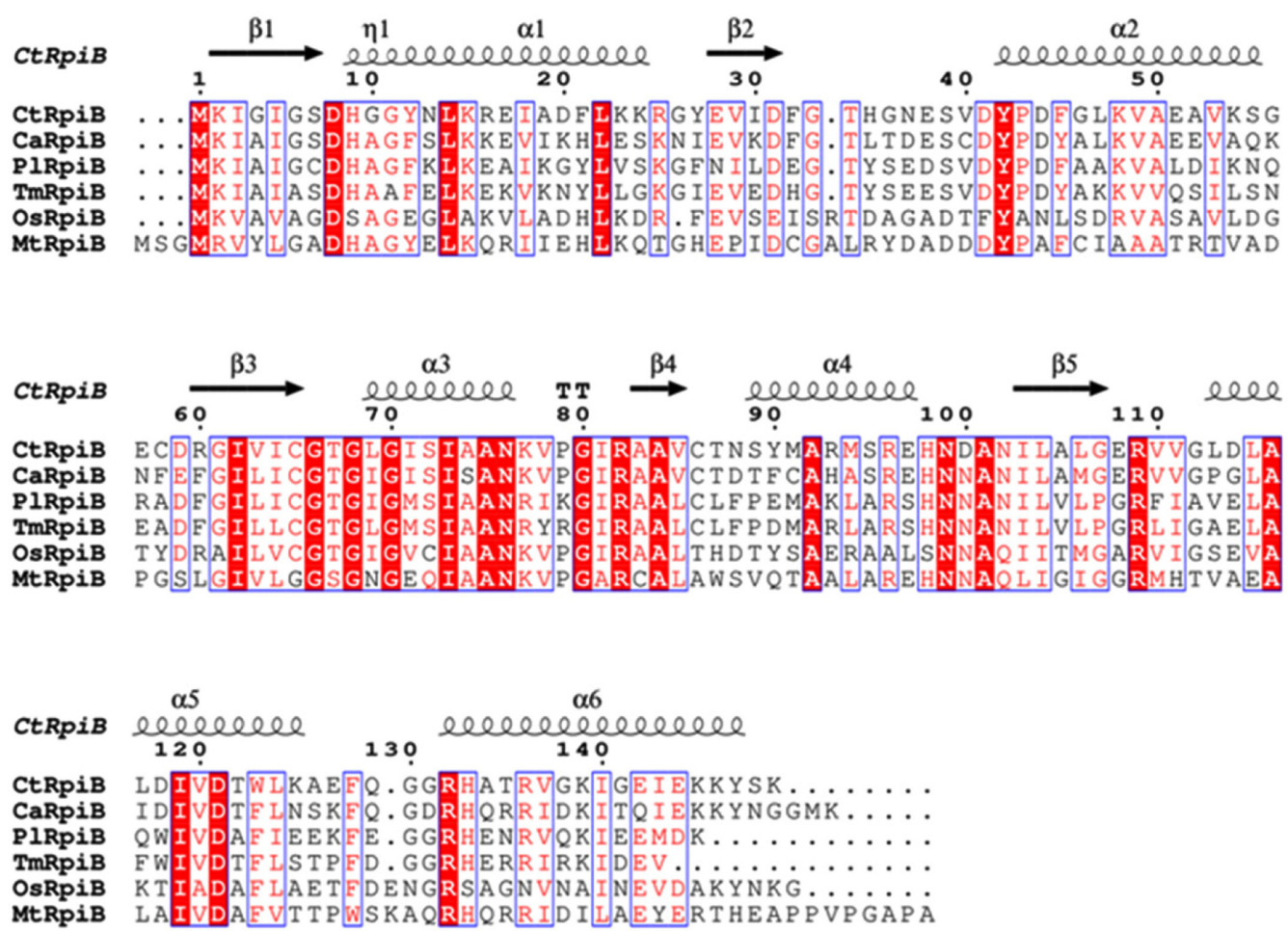

Fig. 2. Alignment of amino acid sequences of ribose-5-phosphate isomerase B from Clostridium acetobutylicum (CaRpiB, NP_349483.1), Thermotoga maritima MSB8 (TmRpiB, NP_228886.1), Clostridium thermocellum (CtRpiB, gi: 266618622), Mycobacterium tuberculosis SK-B (MtRpiB, gi: 620743667), Pseudothermotoga lettingae TMO (PIRpiB, gi: 157313812), and Ochrobactrum sp. CSL1 (OsRpiB).

Alignment was prepared with CLUSTALW (http://www.ebi.ac.uk/Tools/msa/clustalw2/) and ESPript (http://espript.ibcp.fr/ESPript/ ESPript/index.php). The red background part represents same amino acid residues, and the blue box represents residue areas with high identity. 


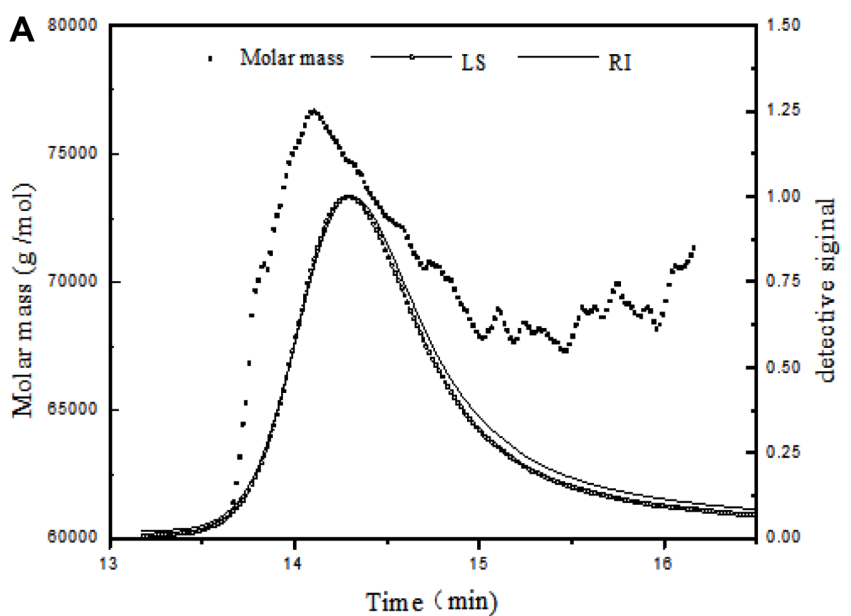

B

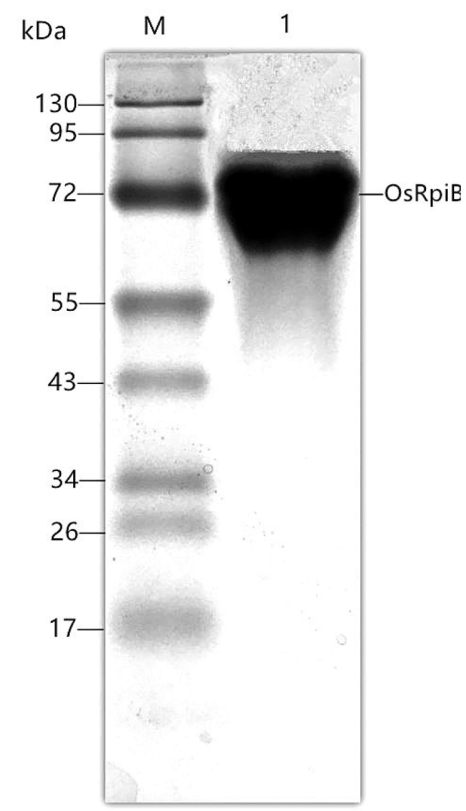

Fig. 3. GPC-MALLS analysis graph and native-PAGE analysis of OsRpiB.

(A) Analytic result of GPC-MALLS. LS represents the chromatogram of OsRpiB with scattering angle 90 degree, and RI represents the chromatogram of OsRpiB with differential refraction. The dots represent molar mass. (B) Native-PAGE analysis of OsRpiB. Lane M: marker proteins; Lane 1: purified OsRpiB.

identity), indicating that it might have different enzymatic properties.

\section{Substrate Specificity of OsRpiB}

Generally, sugar isomerases can catalyze the isomerization of various monosaccharides owing to their broad substrate specificity [3]. Several monosaccharides, including D-allose, D-arabinose, D-ribose-5-phosphate, L-ribose, and L-rhamnose,
Table 1. Substrate specificity of OsRpiB.

\begin{tabular}{lc}
\hline Substrate $(6 \mathrm{mM})$ & Relative activity $(\%)$ \\
\hline L-Ribose & 100 \\
D-Ribose-5-phosphate & 92.7 \\
D-Allose & 79.9 \\
D-Xylose & 59.4 \\
L-Rhamnose & 29.5 \\
D-Arabinose & 29.1 \\
\hline
\end{tabular}

One hundred spercent activity $=6,000 \pm 3.4 \mathrm{nmol} \mathrm{mg}^{-1} \mathrm{~min}^{-1}$

were tested with OsRpiB. As per the results shown in Table 1, OsRpiB had the highest activity with L-ribose among all tested monosaccharides and lower activity against D-ribose-5-phosphate $(92.7 \%)$, D-allose $(79.9 \%)$, D-xylose (59.4\%), L-rhamnose (29.5\%), and D-arabinose (29.1\%). For the pentoses, OsRpiB showed various activities on four kinds of substrate. Both phosphorylated and unphosphorylated ribose substrates showed similar and high affinity with OsRpiB, whereas D-xylose and D-arabinose showed lower activity, probably because the strain Ochrobactrum sp. CSL1 was screened using L-ribose as the sole carbon source. Interestingly, reports stated that RpiB showed substrate specificity on the stereo conformation of the C2 atom [19], but in this case, two kinds of $\mathrm{C} 2$ conformation could be catalyzed by OsRpiB (Fig. 4). For the hexoses, several reports showed that RpiBs from different strains such as T. lettingae TMO, C. thermocellum [8], C. difficile, and T. maritima [10] could be applied in D-allose preparation. However, no literature has reported the affirmative synthesis of L-rhamnulose from L-rhamnose by ribose-5-phosphate isomerases. Furthermore, in studying the RpiB from C. thermocellum, the activity on L-rhamnose was not detected, although it could catalyze the isomerization of D-allose [8]. Moreover, the biotechnological production of L-rhamnulose was carried out mainly by L-rhamnose isomerase catalysis [7]. Therefore, this result expanded the substrate scope of RpiB to deoxy sugars for the first time. Our findings may allow ribose-5-phosphate isomerase to be used as a candidate for further creating novel sugar isomerases. In view of the important use of L-rhamnulose in the food industry, we chose L-rhamnose as the substrate for the following enzymatic characteristic research.

\section{Reaction and Enzymatic Properties of OsRpiB}

The reaction conditions of converting L-rhamnose by OsRpiB were optimized to investigate whether OsRpiB had the potential of producing L-rhamnulose practically. The 
Hexoses:

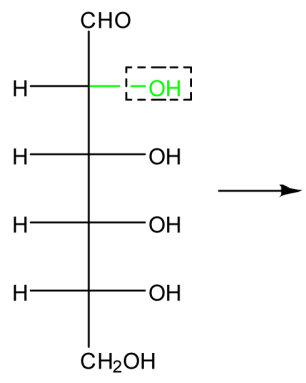

D-Allose

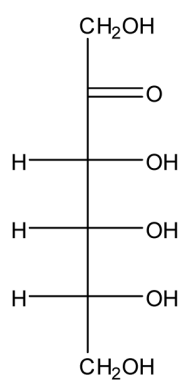

D-Psicose

Pentoses:

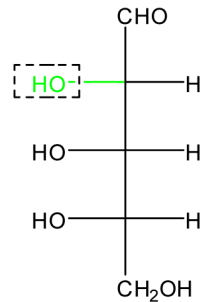

L-Ribose

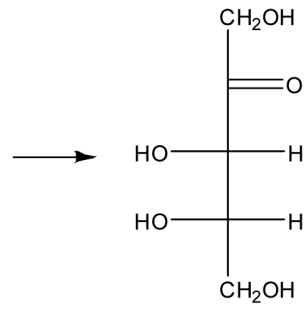

L-Ribulose
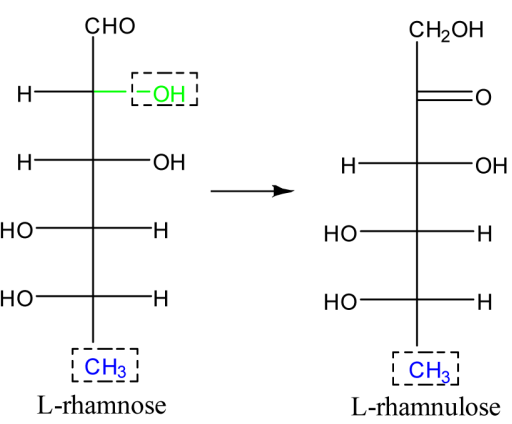

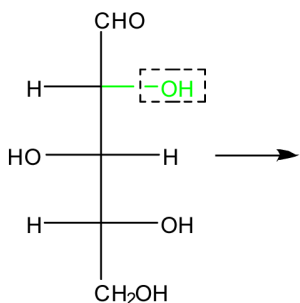

D-Xylose

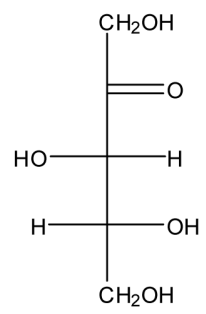

D-Xylulose

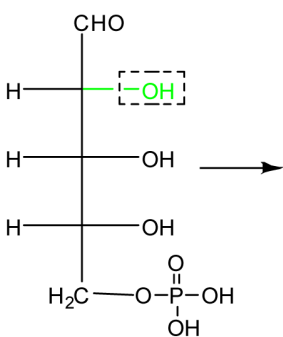

D-ribose-5-phosphate

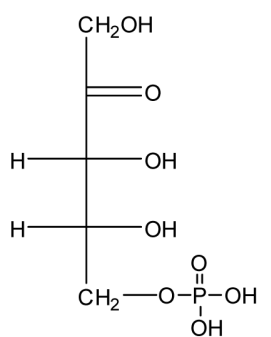

D-ribulose-5-phosphate

Fig. 4. Substrate specificity of OsRpiB.

purified RpiB showed optimal activity at $\mathrm{pH} 8.0$ and $50^{\circ} \mathrm{C}$ in phosphate buffer (Figs. 5A and 5B) for L-rhamnulose production. As no reports existed on using RpiB to prepare L-rhamnulose, the reaction conditions of other substrates were compared. For example, the conditions were $\mathrm{pH} 8.0$ and temperature $70^{\circ} \mathrm{C}$ for using RpiB from T. maritima for L-talose isomerization [9], $\mathrm{pH} 7.5$ and $65^{\circ} \mathrm{C}$ for using $\mathrm{RpiB}$ from $C$. thermocellum for D-allose production [8], and $\mathrm{pH} 8.0$ and $75^{\circ} \mathrm{C}$ for using $\mathrm{RpiB}$ from $T$. lettingae for $\mathrm{D}$-allose production [20]. It could be found that the reaction $\mathrm{pH}$ was similar, but the reaction temperature was significantly lower in the case of OsRpiB. The relative activities of OsRpiB were investigated in the presence of several divalent metal ions, which were added to a final concentration of $1 \mathrm{mM}$. As shown in Fig. 5C, OsRpiB showed the highest activity in the presence of $\mathrm{Ca}^{2+} . \mathrm{Mg}^{2+}$ and $\mathrm{Cu}^{2+}$ also showed activation effects, whereas $\mathrm{Mn}^{2+}$ and $\mathrm{Ba}^{2+}$ made no difference. No activity was found with $\mathrm{Zn}^{2+}$. The OsRpiB activity increased by $16 \%, 11 \%$, and $7 \%$, when the reaction system contained $\mathrm{Ca}^{2+}, \mathrm{Cu}^{2+}$, and $\mathrm{Mg}^{2+}$, respectively. In particular, the effects of $1 \mathrm{mM} \mathrm{Ca}^{2+}, \mathrm{Cu}^{2+}, \mathrm{Mg}^{2+}$, and EDTA were also investigated in this study. The addition of $\mathrm{Ca}^{2+}$ ion to EDTA-treated enzyme enhanced the OsRpiB activity, and the EDTAtreated enzyme in the presence of $1 \mathrm{mM} \mathrm{Ca}^{2+}$ also showed $125 \%$ activity relative to that without the addition of metal ions. Moreover, the enzyme still retained $92.50 \%$ of native 
A

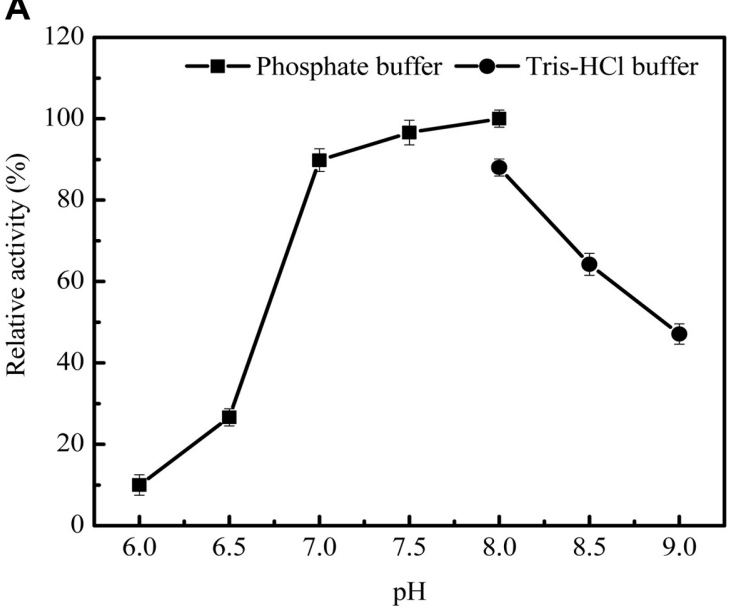

C

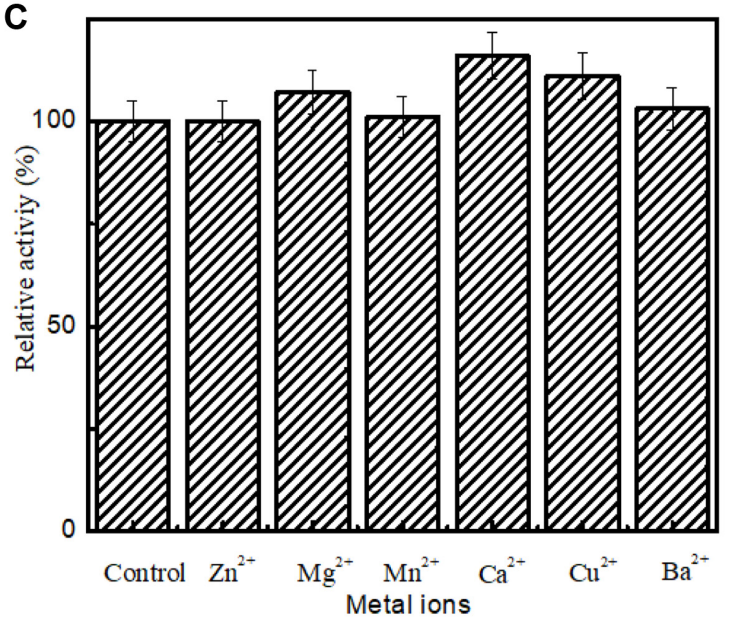

B

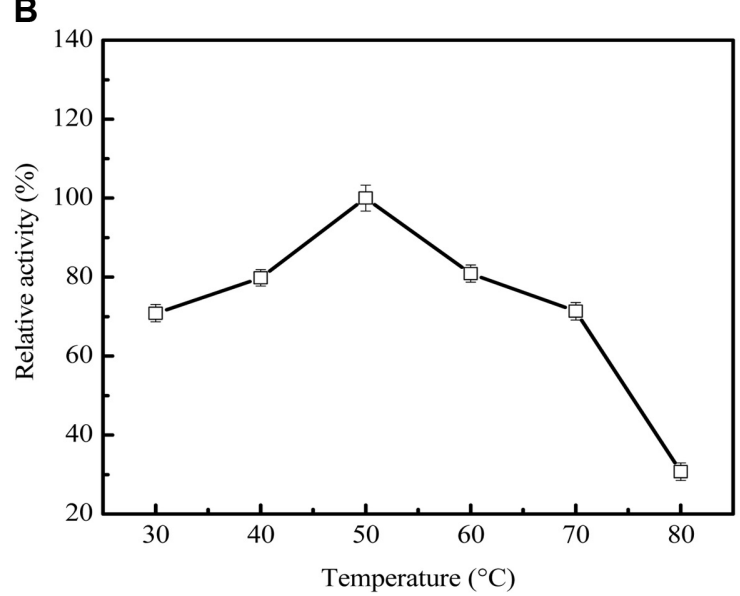

D

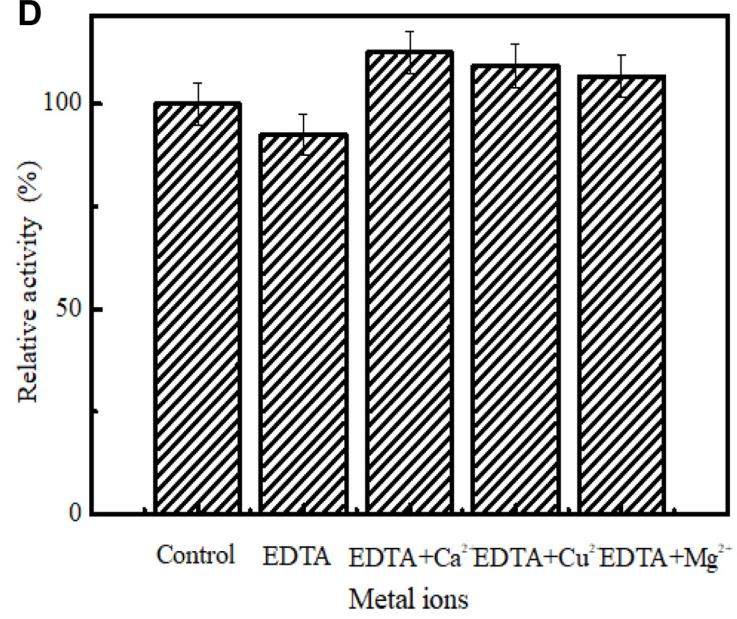

Fig. 5. Effects of different reaction conditions on the activity of OsRpiB;

(A) The relative activity of OsRpiB was investigated at $50^{\circ} \mathrm{C}$ and different $\mathrm{pH}$ values. The two buffer systems used in the experiment were phosphate buffer $(50 \mathrm{mM}, \mathrm{pH} 6.0-8.0)$ and Tris- $\mathrm{HCl}$ buffer $(50 \mathrm{mM}, \mathrm{pH} 8.0-9.0)$. All the experiments were conducted in triplicate. One hundred

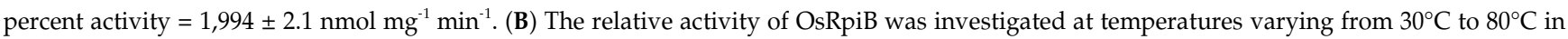
phosphate buffer ( $\mathrm{pH}$ 8.0). All the experiments were conducted in triplicate. One hundred percent activity $=2,000 \pm 3.3 \mathrm{nmol} \mathrm{mg}^{-1} \mathrm{~min}^{-1}$. (C) The relative activity of OsRpiB was investigated at $50^{\circ} \mathrm{C}$ in phosphate buffer $(\mathrm{pH} 8.0)$ with different metal ions. One hundred percent activity $=2,001 \pm$ $5 \mathrm{nmol} \mathrm{mg} \mathrm{min}^{-1}$. (D) Effects of EDTA-treated enzyme or addition of metal ion to EDTA-treated enzyme on enzyme activity. One hundred percent activity $=2,001 \pm 5 \mathrm{nmol} \mathrm{mg}^{-1} \mathrm{~min}^{-1}$.

enzyme activity after treatment with EDTA (Fig. 5D). Therefore, these results distinctly indicated that bivalent metal ions, especially $\mathrm{Ca}^{2+}$ and $\mathrm{Cu}^{2+}$, are essential for the OsRpiB activity. It was reported that most of the phosphosugar isomerases were metal-independent enzymes. For example, the enzyme was not activated by monovalent or divalent cations in producing D-allose from D-psicose catalyzed by RpiB [8]. Interestingly, L-RhIs from E. coli, Pseudomonas stutzeri, Bacillus pallidus, Caldicellulosiruptor saccharolyticus, T.maritima, and D.turgidum have been reported as $\mathrm{Mn}^{2+}$-dependent enzymes [7, 20-25].

Kinetic parameters, such as Michaelis-Menten constant $\left(K_{\mathrm{m}}\right)$, turnover number $\left(k_{\text {cat }}\right)$, and catalytic efficiency $\left(k_{\text {cat }} / K_{\mathrm{m}}\right)$, for the substrate L-rhamnose were calculated using Lineweaver-Burk plots. Table 2 shows the kinetic parameters of OsRpiB and other L-RhIs from different microbials in producing L-rhamnulose. C. saccharolyticus L-RhI has the lowest $K_{\mathrm{m}}$ value toward L-rhamnose, and Bacillus halodurans $\mathrm{L}-\mathrm{RhI}$ has the highest $K_{\mathrm{m}}$ value. In this study, the OsRpiB $K_{\mathrm{m}}$ value for L-rhamnose was determined to be $43.47 \mathrm{mM}$. 
Table 2. Kinetic parameters for L-rhamnose of L-RhIs and RpiB from different organisms.

\begin{tabular}{|c|c|c|c|c|}
\hline Enzyme and organism & $K_{\mathrm{m}}(\mathrm{mM})$ & $k_{\text {cat }}\left(\sec ^{-1}\right)$ & $k_{\mathrm{cat}} / K_{\mathrm{m}}\left(\mathrm{mM}^{-1} \sec ^{-1}\right)$ & Reference \\
\hline $\begin{array}{l}\text { Bacillus pallidus } \\
\text { L-RhI }\end{array}$ & 4.89 & 68 & 13.9 & $\begin{array}{c}\text { Poonperm et al. } \\
\text { [23] }\end{array}$ \\
\hline $\begin{array}{l}\text { Thermotoga maritime } \\
\text { L-RhI }\end{array}$ & 37 & 146 & 3.95 & $\begin{array}{l}\text { Park et al. } \\
\quad[24]\end{array}$ \\
\hline $\begin{array}{l}\text { Thermoanaerobacterium saccharolyticum } \\
\text { L-RhI }\end{array}$ & 3.53 & 180 & 50.8 & $\begin{array}{l}\text { Lin et al. } \\
\text { [26] }\end{array}$ \\
\hline $\begin{array}{l}\text { Caldicellulosiruptor saccharolyticus } \\
\text { L-RhI }\end{array}$ & $1.03 \pm 0.2$ & $99.9 \pm 2.4$ & $97.1 \pm 17.3$ & $\begin{array}{l}\text { Lin et al. } \\
\text { [25] }\end{array}$ \\
\hline $\begin{array}{l}\text { Bacillus halodurans } \\
\text { L-RhI }\end{array}$ & 528 & 150 & 0.28 & $\begin{array}{l}\text { Prabhu et al. } \\
\text { [27] }\end{array}$ \\
\hline $\begin{array}{l}\text { Dictyoglomus turgidum } \\
\text { L-RhI }\end{array}$ & $24.6 \pm 0.4$ & $195 \pm 2.3$ & $7.9 \pm 0.15$ & $\begin{array}{l}\text { Kimet al. } \\
\text { [7] }\end{array}$ \\
\hline $\begin{array}{l}\text { Caldicellulosiruptor obsidiansis } \\
\text { L-RhI }\end{array}$ & $3.54 \pm 0.5$ & $199.7 \pm 1.1$ & $56.4 \pm 1.3$ & $\begin{array}{l}\text { Chen et al. } \\
\text { [4] }\end{array}$ \\
\hline $\begin{array}{l}\text { Ochrobactrum sp. } \\
\text { CSL1 RpiB }\end{array}$ & $43.47 \pm 1.2$ & $129.4 \pm 1.4$ & $2.98 \pm 0.7$ & This study \\
\hline
\end{tabular}

The $v_{\max }$ value and catalytic efficiency $\left(k_{\text {cat }} / K_{\mathrm{m}}\right.$ value) for L-rhamnose were $111.1 \mathrm{U} / \mathrm{mg}$ and $2.98 \mathrm{mM} / \mathrm{sec}$, respectively. Compared with these L-RhIs, OsRpiB shows moderate affinity and catalytic efficiency to its unnatural substrate L-rhamnose and has the potential for the production of L-rhamnulose practically. On the other hand, it is necessary to emphasize that OsRpiB exhibited broadened substrate specificity, which has not been previously reported. The discovery of a novel biocatalyst can help to understand the catalytic mechanism and facilitate bioconversion processes to produce rare sugar.

\section{Bioconversion of L-Rhamnose into L-Rhamnulose by OsRpiB}

The time course of L-rhamnulose production using OsRpiB was monitored under optimal conditions to investigate its equilibrium ratio against L-rhamnose. The reaction was performed at $\mathrm{pH} 8.0$ and $50^{\circ} \mathrm{C}$ with $6 \mathrm{mM}$ L-rhamnose and $1 \mathrm{mM} \mathrm{Ca}^{2+}$ for an extended period (0-12 h). After $1 \mathrm{~h}, 50 \mu \mathrm{l}$ of the enzyme (the same enzyme $20 \mathrm{mg} / \mathrm{ml}$ ) was added to continue the reaction every hour. As shown in Fig. 6 around 26\% L-rhamnose was transformed into L-rhamnulose, without obvious miscellaneous peaks observed in the HPLC diagram in Fig. 7. The enzymatic production of L-rhamnulose by L-RhI from Caldicellulosiruptor obsidiansis OB47 displayed an interesting result. After adding 25 and $50 \mathrm{~g} / 1$ L-rhamnose, a conversion of $44.0 \%$ and $38.6 \%$ was achieved after 2.5 and $3.5 \mathrm{~h}$, yielding 11.0 and $19.3 \mathrm{~g} / \mathrm{l}$ L-rhamnulose, respectively. The biological production of
L-rhamnulose by L-RhI from C. obsidiansis OB47 suggested that the different substrate concentrations exhibited influence on conversion. The higher concentration that led to lower conversion with time elapsing might be due to the product inhibition [4]. Aldose-ketose isomerization by the enzymatic method is reversible, and its reaction equilibrium is unfavorable for ketose formation [5].

The L-RhI from D. turgidum DSMZ 6724 could constantly

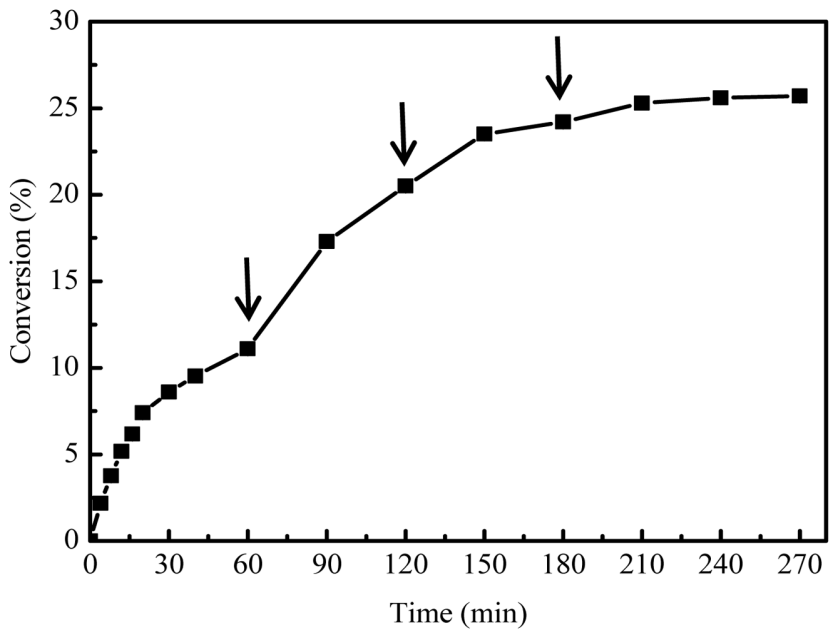

Fig. 6. Time course of bioconversion of L-rhamnose into L-rhamnulose by OsRpiB.

The enzyme concentration was $1 \mathrm{mg} / \mathrm{ml}$. The arrow represents that after $1 \mathrm{~h}, 50 \mu \mathrm{l}$ of enzyme was added every hour; the concentration of the enzyme was $20 \mathrm{mg} / \mathrm{ml}$. 


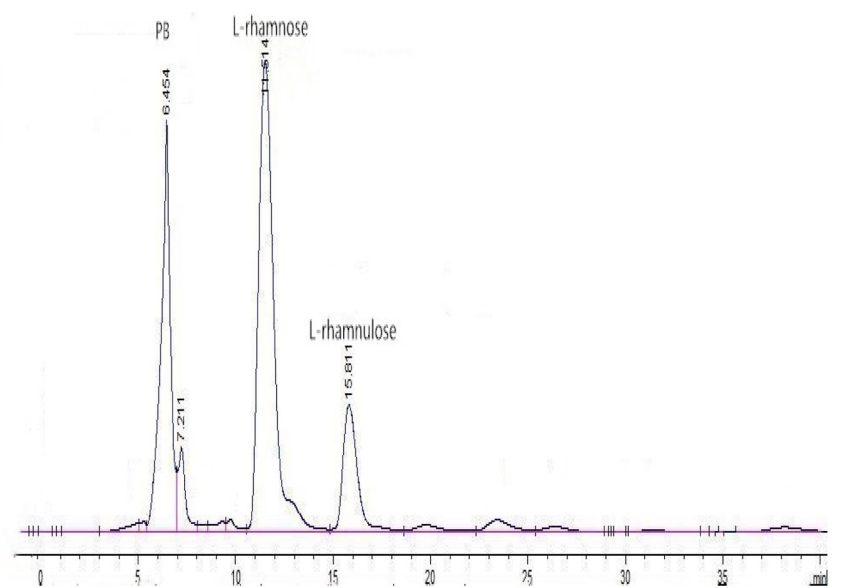

Fig. 7. HPLC analysis of the isomerization product L-rhamnulose catalyzed by OsRpiB.

produce an average of $130 \mathrm{~g} / 1 \mathrm{~L}-\mathrm{rhamnulose}$ from $300 \mathrm{~g} / 1$ L-rhamnose, with a conversion of $43 \%$ by the immobilized enzyme at $\mathrm{pH} 8.0$ and $70^{\circ} \mathrm{C}$ in a bioreactor [7]. Although the conversion of OsRpiB is not higher than L-RhI in this study, the optimal temperature of RpiB used for L-rhamnulose bioconversion saved energy and cost in industrial production.

In addition, as seen from the results of alignment in Fig. 2, other RpiBs all have histine residues on the site of 98 and 133, which are responsible for the ring opening of pyranose and furanose substrates [28], but it is changed to Ser98 and Ser133 in OsRpiB, which might explain the relatively lower reaction efficiency for L-rhamnose. As we know, linear molecules make a tiny partition of total molecules, and the lack of ring-opening residues would lower the concentration of available substrate significantly, which might be a major reason for the relatively low reaction rate. Mutation of the ring-opening histine residue and its near residue of other sugar isomerase and heavy metal inhibition experiments also supported this conclusion $[29,30]$. This speculation urged us to model the 3-D structure of OsRpiB using CtRpiB as the template with the SWISSMODEL online server (https:/ / www.swissmodel.expasy.org/ interactive). After inspection and comparison of the active sites of OsRpiB and CtRpiB, it could be found that the residues Arg 136A and Asp 41B in CtRpiB may have polar and electronic interactions with the phosphate group of the substrate ribose-5-phosphate (Fig. 8A), in which Arg 136A responds for direct interaction and Asp 41B functions by induction effect. In OsRpiB, the corresponding residues were changed to Asn 137A and Phe 41B, meaning that it might have the ability to accept aliphatic group substrates (i.e., L-rhamnose) (Fig. 8B), which provide a possible

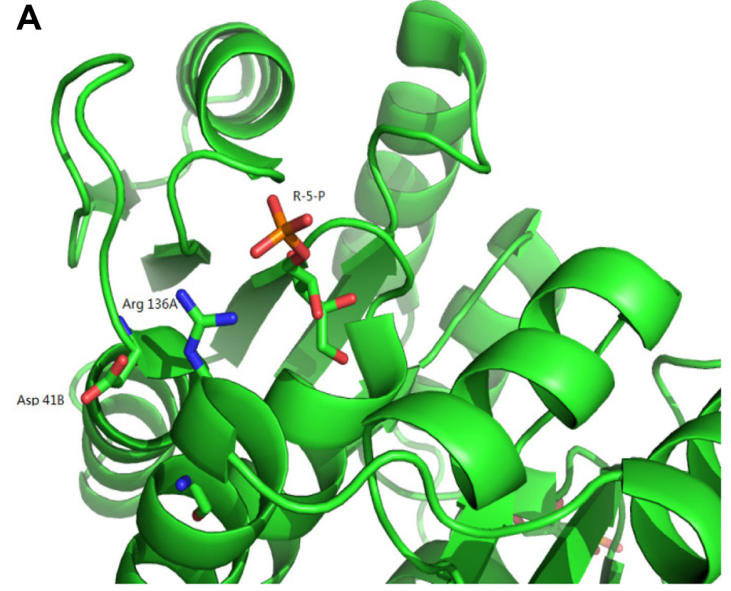

B

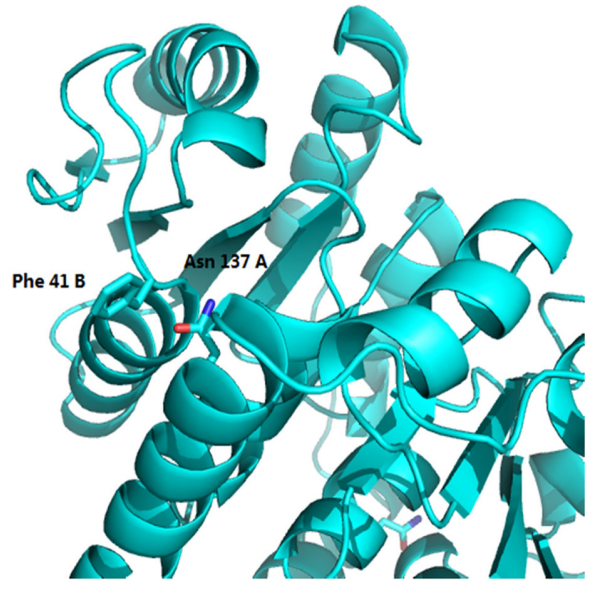

C

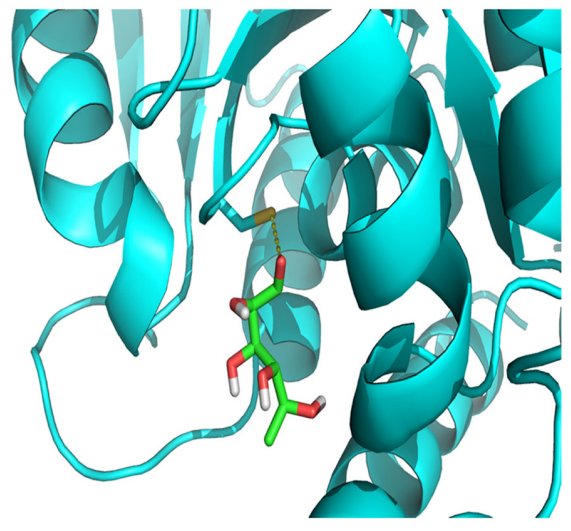

Fig. 8. Structure of OsRpiB and CtRpiB near the active site, where the active sites (indicated by linear sugar molecules) are located between the two subunits (chain A and chain B), with residues contributed by both.

(A) Active site of CtRpiB, in which the substrate ribose-5-phosphate, Arg 136A, and Asp 41B are marked. (B) The same view of the active site from the simulated model of OsRpiB, where the corresponding residues Asn 137A and Phe 41B are marked. (C) The docking result of the OsRpiB model and linear substrate of L-rhamnose; the dash line is the distance between the thiol group of catalytic residue Cys 65A and the $\mathrm{C} 1$ hydroxy group of the substrate. 
explanation for the unconventional reactivity of OsRpiB for L-rhamnose. Docking analysis of the built model and L-rhamnose was carried out by the Autodock vina program. The results showed a near distance between the thiol group of catalytic residue Cys $65 \mathrm{~A}$ and the $\mathrm{C} 1$ hydroxy group of the substrate of $3.7 \AA$ (Fig. 8C), meaning the possibility of activity. Asn137A also makes sufficient space for the C6 methyl group of L-rhamnose.

Further efforts should be made to improve the conversion so as to adapt to industrialized production. The activity of the enzyme can be improved by analyzing the structure of the enzyme and designing mutation active sites, and the stability of the enzyme can be increased by immobilization.

\section{Acknowledgments}

The authors are grateful for the financial support from the National Natural Science Foundation of China (Grant Nos. 21376156 and 21676173). This study was also supported by the Qing Lan Project of Jiangsu Education Department. Moreover, the project was also funded by the Priority Academic Program Development of Jiangsu Higher Education Institutions. The authors are grateful for the financial support from the agricultural infrastructure project of Suzhou science and technology development plan (SYN201507). This research was also supported by the Foundation of Suzhou University Science and Technology (No. XKZ201411).

\section{Conflict of Interest}

The authors have no financial conflicts of interest to declare.

\section{References}

1. Zhang W, Zhang T, Jiang B, Mu W. 2017. Enzymatic approaches to rare sugar production. Biotechnol. Adv. 35: 267-274.

2. Shompoosang S, Yoshihara A, UechiK, Asada Y, Morimoto K. 2016. Novel process for producing 6-deoxy monosaccharides from L-fucose by coupling and sequential enzymatic method. J. Biosci. Bioeng. 121: 1-6.

3. Beerens K, Desmet T, Soetaert W. 2012. Enzymes for the biocatalytic production of rare sugars. J. Ind. Microbiol. Biotechnol. 39: 823-834.

4. Chen Z, Xu W, Zhang W, Zhang T, Jiang B, Mu W. 2018. Characterization of a thermostable recombinant L-rhamnose isomerase from Caldicellulosiruptor obsidiansis OB47 and its application for the production of L-fructose and L-rhamnulose.
J. Sci. Food. Agric. 98: 2184-2193.

5. Wen L, Zang L, Huang K, Li S, Wang R, Wang PG. 2016. Efficient enzymatic synthesis of L-rhamnulose and L-fuculose. Bioorg. Med. Chem. Lett. 26: 969-972.

6. Shompoosang S, Yoshihara A, Uechi K, Asada Y, Morimoto K. 2014. Enzymatic production of three 6-deoxy-aldohexoses from L-rhamnose. Biosci. Biotechnol. Biochem. 78: 317-325.

7. Kim YS, Shin KC, Lim YR, Oh DK. 2013. Characterization of a recombinant L-rhamnose isomerase from Dictyoglomus turgidum and its application for L-rhamnulose production. Biotechnol. Lett. 35: 259-264.

8. Park CS, Yeom SJ, Kim HJ, Lee SH, Lee JK, Kim SW, Oh DK. 2007. Characterization of ribose-5-phosphate isomerase of Clostridium thermocellum producing D-allose from D-psicose. Biotechnol. Lett. 29: 1387-1391.

9. Lee TE, Shin KC, Oh DK. 2018. Biotransformation of fructose to allose by one-pot reaction using Flavonifractor plautii D-allulose 3-epimerase and Clostridium thermocellumribose 5-phosphate isomerase. J. Microbiol. Biotechnol. 28: 418-424.

10. Yeom SJ, Kim BN, Park CS, Oh DK. 2010. Substrate specificity of ribose-5-phosphate isomerases from Clostridium difficile and Thermotoga maritima. Biotechnol. Lett. 32: 829-835.

11. Park CS, Yeom SJ, Lim YR, Kim YS, Oh DK. 2011. Substrate specificity of a recombinant ribose-5-phosphate isomerase from Streptococcus pneumoniae and its application in the production of L-lyxose and L-tagatose. World. J. Microbiol. Biotechnol. 27: 743-750.

12. Morimoto K, Terami Y, Maeda Y, Yoshihara A, Takata G, Izumori K. 2013. Cloning and characterization of the L-ribose isomerase gene from Cellulomonas parahominis MB426. J. Biosci. Bioeng. 115: 377-381.

13. Bradford MM. 1976. A rapid and sensitive method for the quantitation of microgram quantities of protein utilizing the principle of protein dye binding. Anal. Biochem. 72: 248-254.

14. Dische Z, Borenfreuod E. 1951. A new spectrophotometric method for the detection and determination of keto sugars and trioses. J. Biol. Chem. 192: 583-587.

15. Mizanur RM, Takada G, Izumori K. 2001. Cloning and characterization of a novel gene encoding L-ribose isomerase from Acinetobacter sp. strain DL-28 in Escherichia coli. Biochim. Biophys. Acta 1521: 141-145.

16. Edwards TE, Abramov AB, Smith ER, Baydo RO, Leonard JT, Leibly DJ, et al. 2011. Structural characterization of a ribose5-phosphate isomerase B from the pathogenic fungus Coccidioides immitis. BMC Struct. Biol. 11: 39.

17. Kaur PK, Tripathi N, Desale J, Neelagiri S, Yadav S, Bharatam PV, et al. 2016. Mutational and structural analysis of conserved residues in ribose-5-phosphate isomerase B from Leishmania donovani: role in substrate recognition and conformational stability. PLoS One 11: e0150764.

18. Essenberg MK, Cooper RA. 1975. Two ribose-5-phosphate isomerases from Escherichia coli K12: partial characterization of the enzymes and consideration of their possible 
physiological roles. Eur. J. Biochem. 55: 323-332.

19. Yeom SJ, Seo ES, Kim YS, Oh DK. 2011. Increased D-allose production by the R132E mutant of ribose-5-phosphate isomerase from Clostridium thermocellum. Appl. Microbiol. Biotechnol. 89: 1859-1866.

20. Feng Z, Mu W, Jiang B. 2013. Characterization of ribose-5phosphate isomerase converting D-psicose to D-allose from Thermotoga lettingae TMO. Biotechnol. Lett. 35: 719-724.

21. Badia J, Gimenez R, Baldomá L, Barnes E, Fessner WD, Aguilar J. 1991. L-Lyxose metabolism employs the L-rhamnose pathway in mutant cells of Escherichia coli adapted to grow on L-lyxose. J. Bacteriol. 173: 5144-5150.

22. Leang K, Takada G, Fukai Y, Morimoto K, Granström TB, Izumori K. 2004. Novel reactions of L-rhamnose isomerase from Pseudomonas stutzeri and its relation with D-xylose isomerase via substrate specificity. Biochim. Biophys. Acta 1674: 68-77.

23. Poonperm W, Takata G, Okada H, Morimoto K, Granström TB, Izumori K. 2007. Cloning, sequencing, overexpression and characterization of L-rhamnose isomerase from Bacillus pallidus Y25 for rare sugar production. Appl. Microbiol. Biotechnol. 76: 1297-1307.

24. Park CS, Yeom SJ, Lim YR, Kim YS, Oh DK. 2010. Characterization of a recombinant thermostable L-rhamnose isomerase from Thermotoga maritima ATCC 43589 and its application in the production of L-lyxose and L-mannose. Biotechnol. Lett. 32: 1947-1953.

25. Lin CJ, Tseng WC, Fang TY. 2011. Characterization of a thermophilic L-rhamnose isomerase from Caldicellulosiruptor saccharolyticus ATCC 43494. J. Agric. Food Chem. 59: 8702-8708.

26. Lin CJ, Tseng WC, Lin TH, Liu SM, Tzou WS, Fang TY. 2010. Characterization of a thermophilic L-rhamnose isomerase from Thermoanaerobacterium saccharolyticum NTOU1. J. Agric. Food Chem. 58: 10431-10436.

27. Prabhu P, Doan TT, Jeya M, Kang LW, Lee JK. 2011. Cloning and characterization of a rhamnose isomerase from Bacillus halodurans. Appl. Microbiol. Biotechnol. 89: 635-644.

28. Jung J, Kim J, Yeom S, Ahn Y, Oh D, Kang L. 2011. Crystal structure of Clostridium thermocellum ribose-5-phosphate isomerase B reveals properties critical for fast enzyme kinetics. Appl. Microbiol. Biotechnol. 90: 517-527.

29. Whitaker RD, Cho Y, Cha J, Carrell HL, Glusker JP, Karplus PA, et al. 1995. Probing the roles of active site residues in D-xylose isomerase. J. Biol. Chem. 270: 22895-22906.

30. Kovalevsky AY, Hanson L, Fisher SZ, Mustyakimov M, Mason SA, Forsyth VT, et al. 2010. Metal ion roles and the movement of hydrogen during reaction catalyzed by D-xylose isomerase: a joint $x$-ray and neutron diffraction study. Structure 18: 688-699. 